\title{
"A Systematic Review on Guidelines and Recommendations for Tracheostomy During COVID-19 Pandemic"
}

\author{
Rahulkumar Shah $^{1}$ (D) G Priyadarshini ${ }^{1} \cdot$ Monil Parsana $^{2}$
}

Received: 25 September 2020/ Accepted: 15 March 2021/Published online: 29 April 2021

(C) Association of Otolaryngologists of India 2021

\begin{abstract}
World is under threat of COVID-19 pandemic, associated with many numbers of critically ill patients. To manage these intubated patients there are need of more ventilators but world is not prepared for this type of situation and there are lacunae of such arrangements in most of the countries. As we know patients cannot be intubated for long time and they should be given preference to alternative airway in the form of tracheostomy. COVID-19 is aerosol transmitted disease which lead to indeed challenge to health care providers to safely perform tracheostomy and provide post tracheostomy care to these patients with minimising risks of nosocomial transmission to themselves and accompanying nursing staff. There are so many guidelines and recommendations for the timing, desired place of tracheostomy, change in tracheostomy steps related to conventional method and the subsequent management of patients. So, the aim of this systematic review is to give a brief review of available data on COVID-19 related to the timing, personal protections, operative steps modifications, and subsequent post tracheostomy care during this pandemic.
\end{abstract}

Keywords COVID-19 · Tracheostomy ·

Personal protective equipment

\section{Abbreviations \\ PAPR Powered air purifying respirators}

Rahulkumar Shah

rahulshah.1010october@gmail.com

1 Department of ENT, Pramukhswami Medical College, Karamsad, Anand, Gujarat 388325, India

2 Department of ENT, Pandit Dindayal Upadhyay Medical College, Rajkot, Gujarat, India
PPE Personal protective equipment

HME Heat and Moisture exchanger

HEPA High efficiency particulate air

PEEP Positive end expiratory pressure

APL Adjustable pressure limiting valve

ET Endotracheal tube

DOP Date of publication

\section{Introduction}

The COVID-19 pandemic caused by the SARS-CoV-2 virus is big health related issue faced by many doctors across world since it began in late 2019 [1]. Till date COVID-19 has infected more than 30.6 million people and cause 950000 deaths [2]. The Doctors are in search for definite treatment and methods for reduction of transmission. Tracheostomies are commonly done in critically ill patients which are on mechanical ventilation to facilitate their weaning from ventilation and to increase the availability of intensive care unit (ICU) beds for new infected patients. However, as we know tracheostomy is an aerosol generating procedure, so health-care workers are at risk of infection during procedure and post tracheostomy care even though appropriate personal protective equipment (PPE) is used. So COVID-19 positive patients are challenge for tracheostomy procedure to be done safely. There are many Conflicting recommendations exist about the timing, ideal place, performance of tracheostomy and the subsequent management of patients. 


\section{Methodolgy}

The report of this systematic review was made according to the recommendations of the Preferred Reporting Items for Systematic Reviews and Meta-Analyses (PRISMA) statement (Fig 1). The review protocol was not previously registered. MEDLINE (accessed from PubMed) from 6 august 2019 to 7 august 2020 were systematically searched for related published articles. In electronic databases, the following search strategy was implemented and these key words (in the title/abstract) were used: "COVID 19" OR "CORONAVIRUS" OR "SARS COV-2" AND "TRACHEOSTOMY". Articles written in English and available full text were all included in this search. All authors participated through each phase of the review independently (screening, eligibility, and inclusion).They independently screened the titles and abstracts yielded by the search against the inclusion criteria. They resolved any disagreement through discussions. Neither of the authors were blind to the journal titles or to the study authors or institutions. The following data were extracted from the included studies: study authors, study designs, main results. We included only human studies and articles with clearly defined clinical outcome. The exclusion criteria was animal studies and review articles. The search was performed at specified date and time on 7/08/2020 at 11:30 Am.

\section{Results}

Total of 56 full article studies were obtained on PubMed database search, out of which 40 studies were excluded due to not relevant title, not relevant content, review articles, head neck oncology related tracheostomy. Finally, we

Fig. 1 PRISMA flow chart

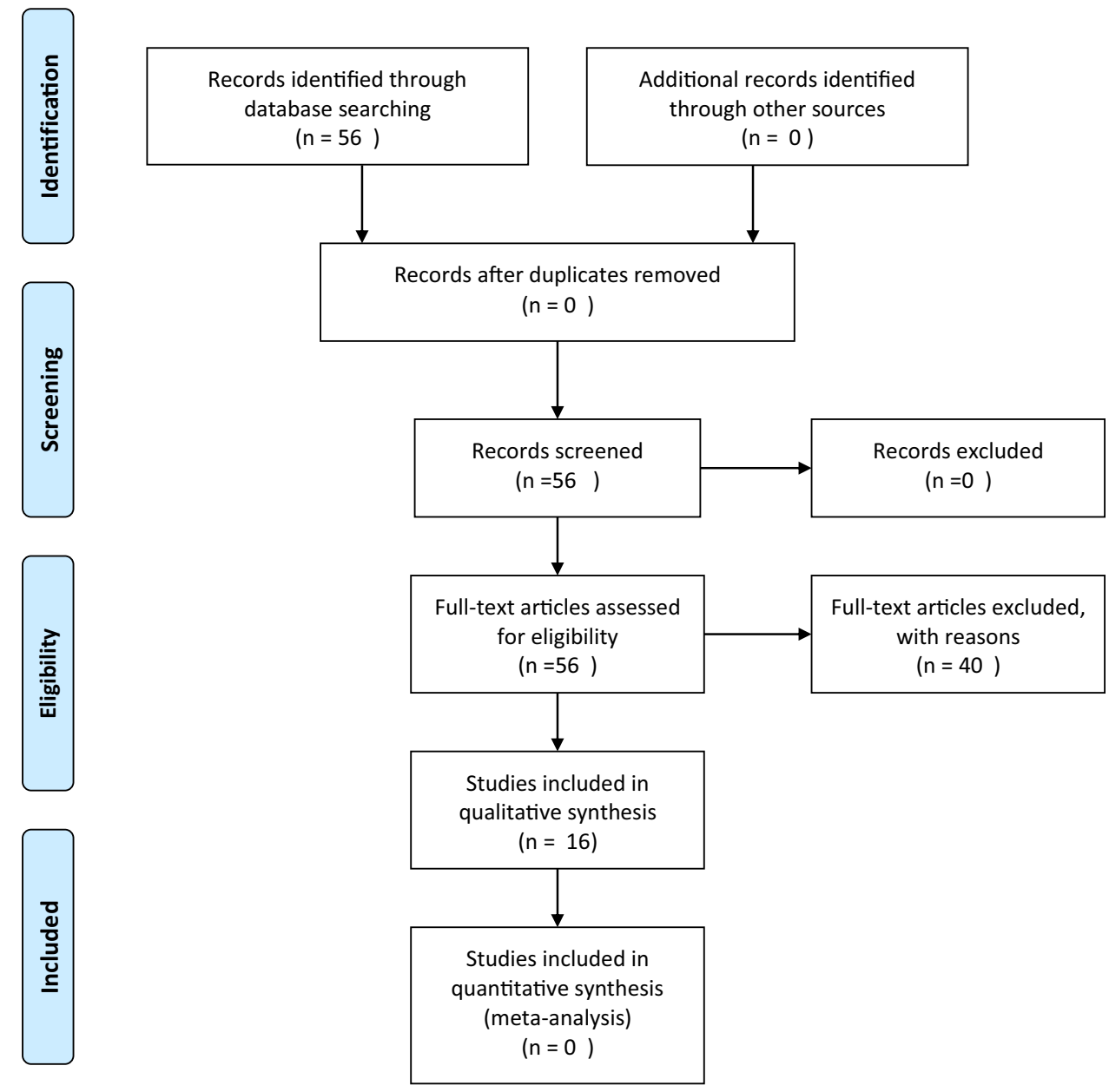

From: Moher D, Liberati A, Tetzlaff J, Altman DG, The PRISMA Group (2009). Preferred Reporting /tems for Systematic Reviews and MetaAnalyses: The PRISMA Statement. PLoS Med 6(7): e1000097. doi:10.1371/journal.pmed1000097

For more information, visit www.prisma-statement.org. 
reviewed the final 15 articles based on our selection criteria to extract the following information from each: first author, date of publication, study design, main results data related to tracheostomy guidelines for COVID-19. The extracted data is jotted in Table 1.

\section{Discussion}

General Recommendations for Tracheostomy in COVID19 positive Patients based on systemic analysis of included articles are developed as under in different headings:

\section{Timing of Tracheostomy}

Timing of tracheostomy should be between ventilator [post intubation] days 14-21 when viral load is expected to be decreasing and 21-30 days after onset of symptoms.

\section{Place of Procedure}

The ideal location for performing a tracheostomy on a COVID-19 positive patient should be an isolated room with lower pressure than the corridor with closed doors-windows and no laminar flow. If not possible, Operating room or ICU room with negative pressure using a portable high efficiency particulate air (HEPA) filtration system can be beneficial.

\section{Preparation and Safety}

Personal protective equipment-PPE should include: Fitted respiratory mask [N95 OR PAAR OR PFF3], surgical cap, impermeable sterile gown, shoe covers, goggles, and fullface shields, sterile double gloves and additional surgical mask (in front of the N95 or PFF3). There should be minimum number of people in the room ( 2 procedural staff-ENT surgeon and anaesthetic). Use only a conventional cuffed tracheostomy tube, avoiding the fenestrated models. If shifting of patient is needed to isolated room or operating room then do deep suctioning of the chest and oral cavity using the closed suctioning circuit to reduce the amount of secretions at the time of opening the trachea. During transfer of patient, Security staff should have to close the corridor temporarily and the patient should be transferred along the back corridor of the theatre [not through the main theatre entrance] and transfer team should have to take all personal protection measures.

\section{Operative Steps/Technique Modification}

- Deep neuromuscular blockade and sedatives should be given for adequate paralysis with glycopyrrolate to reduce tracheal secretions.

- Avoid electrocautery usage during tracheostomy procedure to reduce risk of smoke formation and viral transmission via aerosol. After trachea identification, Pre oxygenate the intubated patient with PEEP and then stop ventilation and turn off flows of ventilation.

- Allow time for passive expiration with open APL valve.

- To avoid the aerosol transmission- clamp ET tube, deflate cuff and push down the ET tube beyond [up to carina] the site chosen for the tracheal stoma at the beginning of the procedure.

- Create appropriate tracheal window opening, deflate the cuff of ET tube and pull the ET tube until the tip is proximal to the tracheal window opening.

- Tracheal or wound suctioning of blood or secretions should not be done, to avoid aerosol generation.

- Insert the tracheostomy tube quickly into the opening, inflate tracheostomy tube cuff almost simultaneously and the tracheostomy tube is rapidly connected to the ventilator with immediate resumption of the ventilation.

- Confirm position of the tracheostomy tube with end tidal $\mathrm{CO} 2$ only to avoid contamination of stethoscope by auscultation.

- An HME type filter (Heat and moisture exchanger) must be placed on the tracheostomy tube to reduce the exposure of the virus, in case of accidental disconnection of circuit and if patient is not on mechanical ventilation.

- Suspension of ventilation support should be minimum, with satisfactory oxygen saturation [do quick tracheostomy].

\section{Post Procedural care and Rehabilitation}

- Team involved in the procedure should use a shower for body cleaning.

- Avoid humidified oxygen, use only HME filters.

- Do suctioning always in a closed circuit.

- Tracheostomy Cuff should be always inflated.

- Avoid tracheostomy stoma dressing changes unless there are clear signs of infection.

- Avoid tracheostomy tube change before 7-10 days, giving preference to a period of lower viral load. During tracheostomy tube change the anaesthesiologist should have to sedate the patient and perform a neuromuscular block to reduce any risk of coughing. 


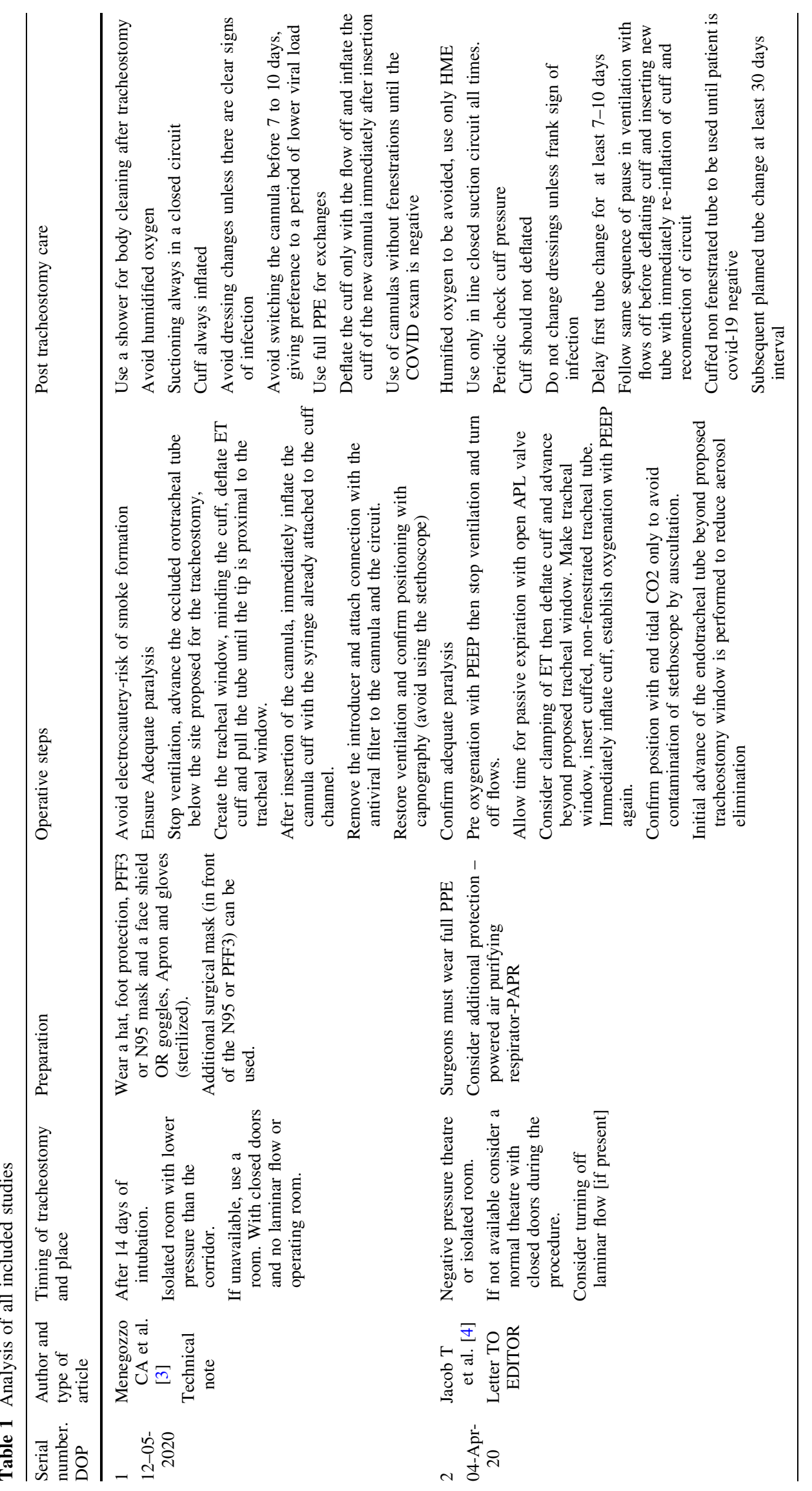




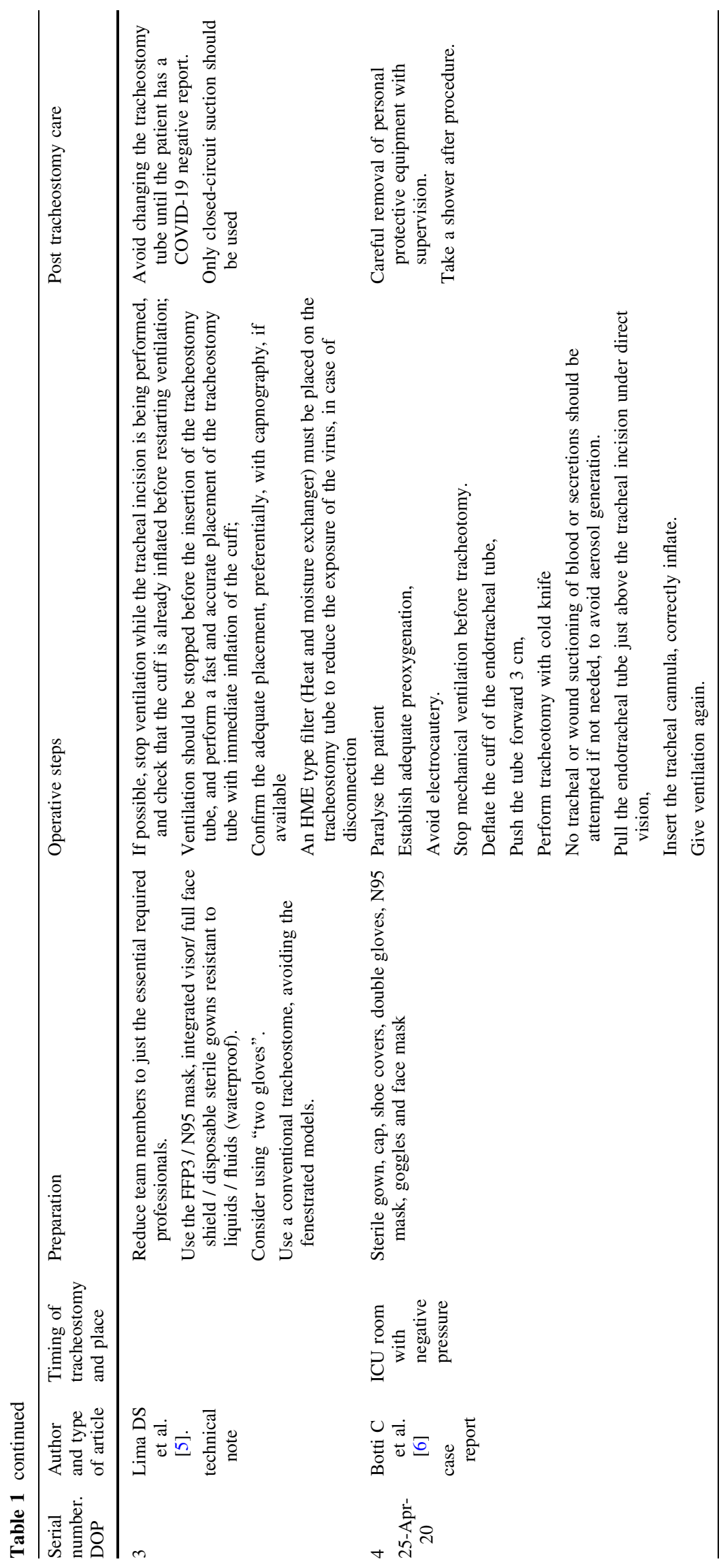




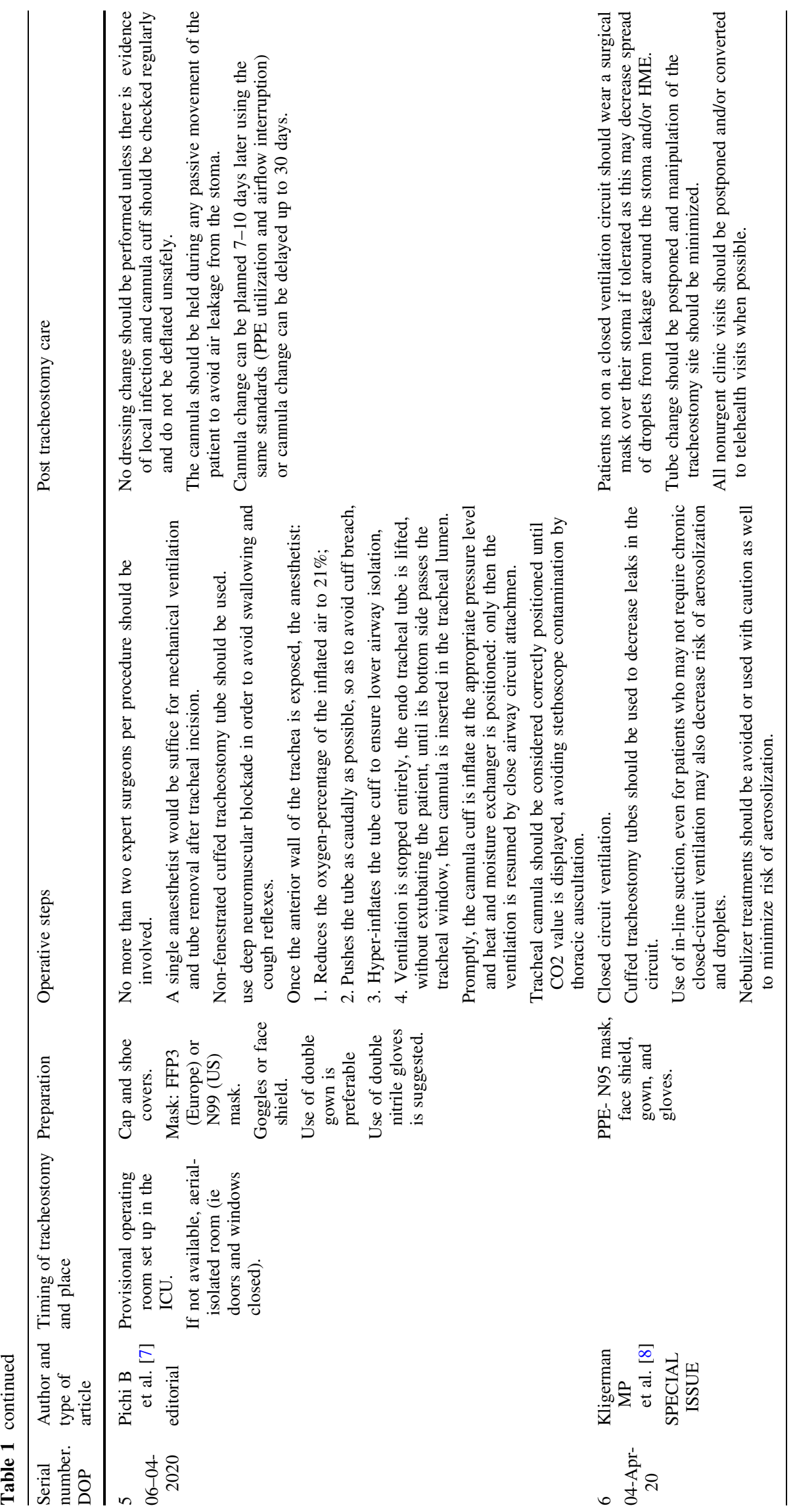




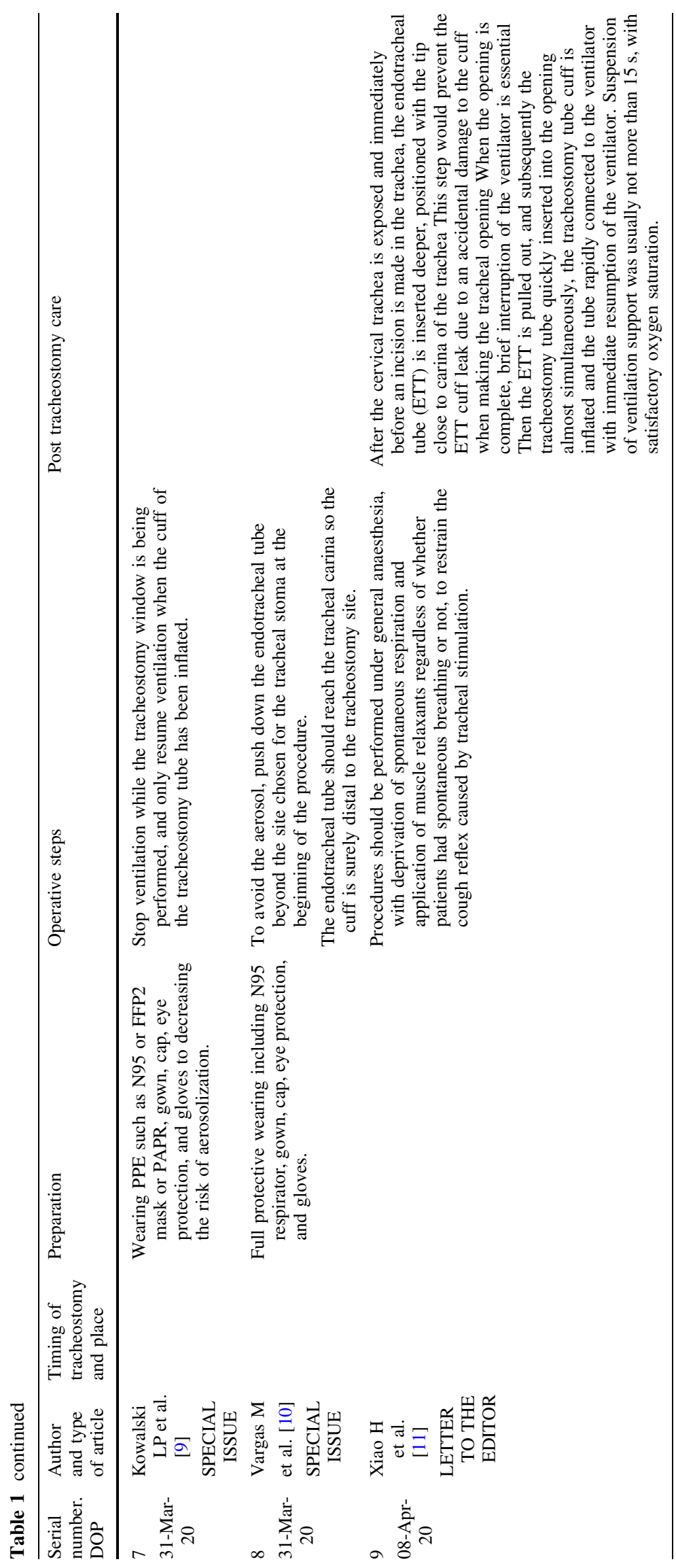




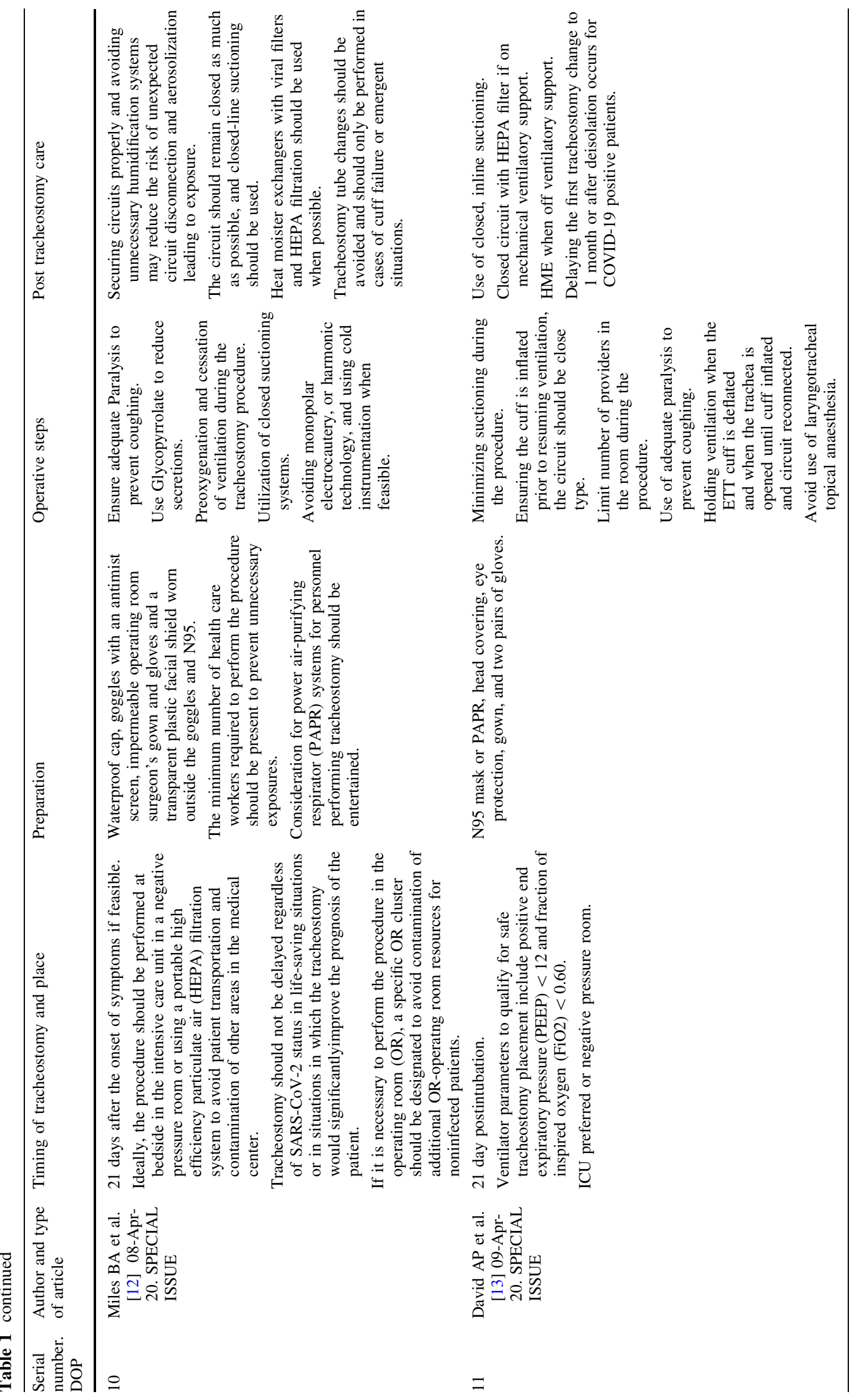




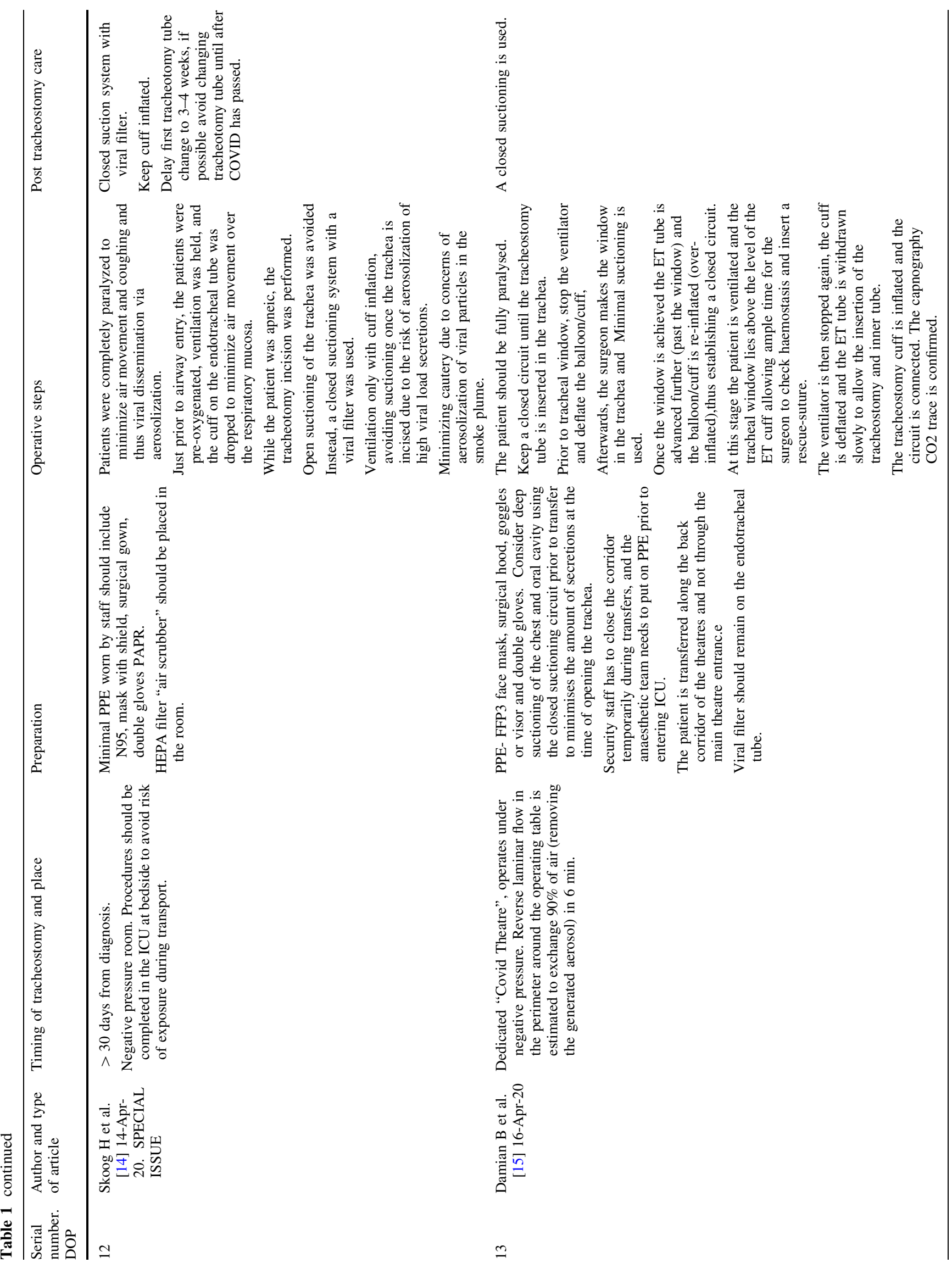




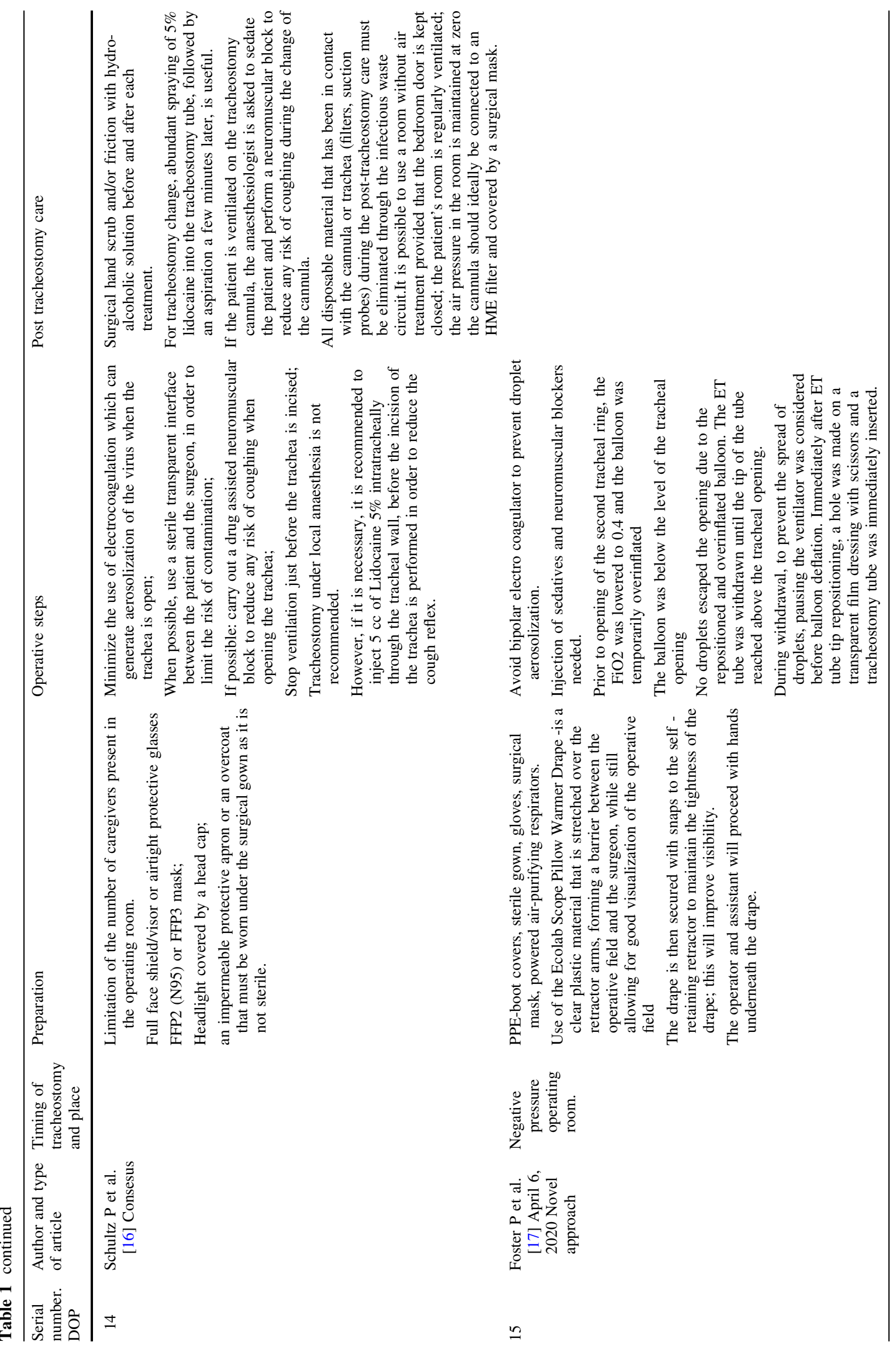




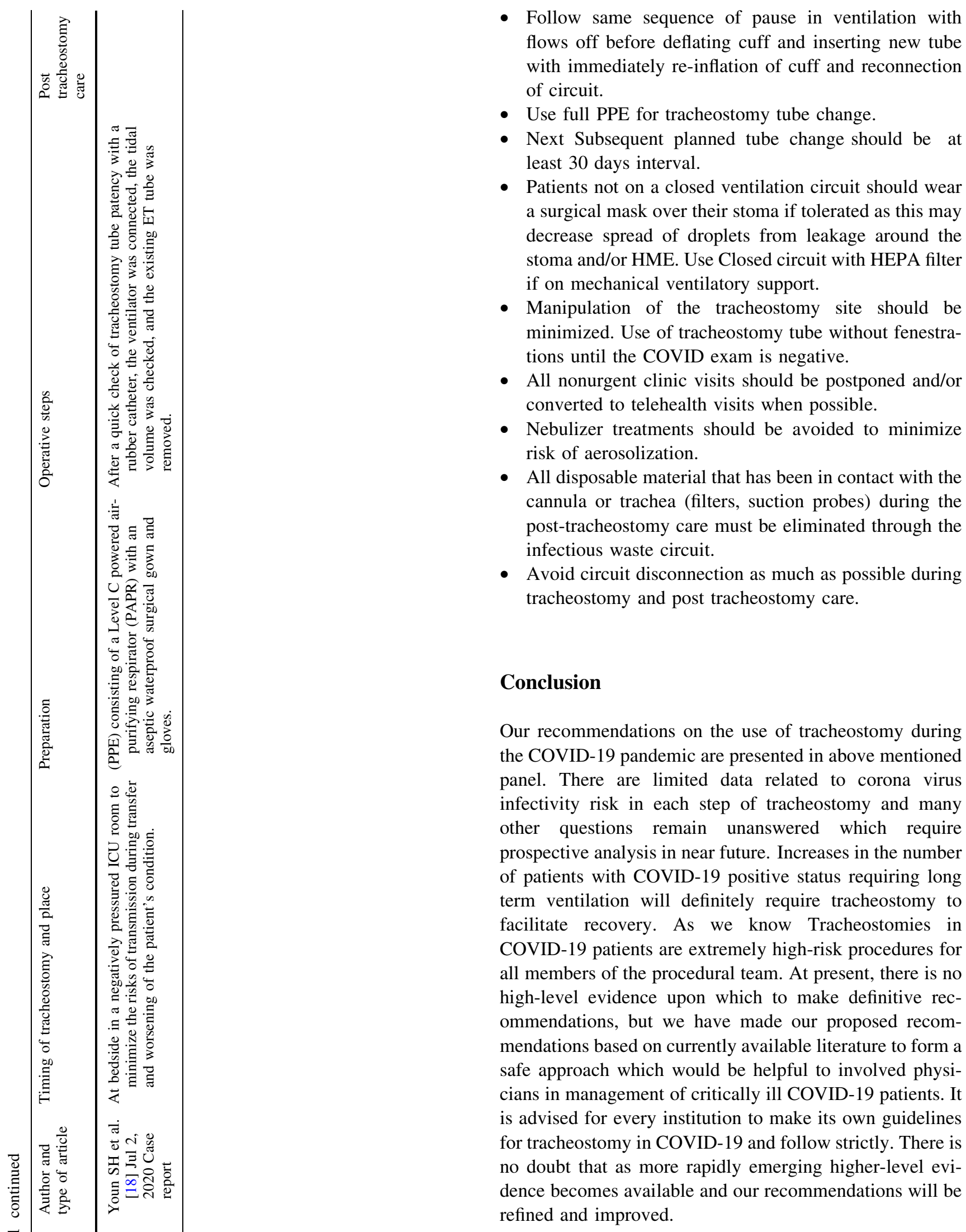




\section{References}

1 Zhu N, Zhang D, Wang W et al. (2020) A novel coronavirus from patients with pneumonia in China, $2019 \mathrm{~N}$ Engl J Med https://doi.org/10.1056/NEJMoa2001017

2 World Health Organization (WHO) Coronavirus disease (COVID19) Pandemic Weekly update on 20 september at $10 \mathrm{am}$

3 Menegozzo CA, Arap SS, Mariani AW, Minamoto H, Imamura R, Bento RF, Pêgo-Fernandes PA, Kowalski LP, Utiyama E (2020) Standardization of elective tracheostomies at the Central Institute of the Hospital das Clínicas in São Paulo during the COVID-19 pandemic. Revista do Colégio Brasileiro de Cirurgiões, 47

4 Jacob T, Walker A, Mantelakis A, Gibbins N, Keane O (2020) A framework for open tracheostomy in COVID-19 patients Clin Otolaryngol 45:649-651

5 Lima DS, Junior MF, Vieira-Jr HM, de Campos T, Di Saverio S. Alternatives for establishing a surgical airway during the COVID19 pandemic

6 Botti C, Lusetti F, Castellucci A, Costantini M, Ghidini A (2020) Safe tracheotomy for patients with COVID-19 Am J Otolaryngol 7:102533

7 Pichi B, Mazzola F, Bonsembiante A, Petruzzi G, Zocchi J, Moretto S, De Virgilio A, Pellini R (2020) CORONA-steps for tracheotomy in COVID-19 patients: a staff-safe method for airway management Oral Oncol 105:104682

8 Kligerman MP, Vukkadala N, Tsang RK, Sunwoo JB, Holsinger FC, Chan JY, Damrose EJ, Kearney A, Starmer HM (2020) Managing head and neck cancer patients with tracheostomy or laryngectomy during the COVID-19 pandemic Head Neck 42(6): 1209

9 Kowalski LP, Sanabria A, Ridge JA, Ng WT, de Bree R, Rinaldo A, Takes RP, Mäkitie AA, Carvalho AL, Bradford CR, Paleri V (2020) COVID-19 pandemic: effects and evidence-based recommendations for otolaryngology and head and neck surgery practice Head Neck 42(6):1259-1267

10 Vargas M, Servillo G (2020) Improving staff safety during tracheostomy in COVID-19 patients Head Neck 42(6):1278-1279
11 Xiao H, Zhong Y, Zhang X, Cai F, Varvares MA (2020) How to avoid nosocomial spread during tracheostomy for COVID-19 patients Head Neck 42(6):1280-1281

12 Miles BA, Schiff B, Ganly I, Ow T, Cohen E, Genden E, Culliney B, Mehrotra B, Savona S, Wong RJ, Haigentz M (2020) Tracheostomy during SARS-CoV-2 pandemic: recommendations from the New York head and neck society Head Neck 42(6): 1282-1290

13 David AP, Russell MD, El-Sayed IH, Russell MS (2020) Tracheostomy guidelines developed at a large academic medical center during the COVID-19 pandemic Head Neck 42(6):1291-1296

14 Skoog H, Withrow K, Jeyarajan H, Greene B, Batra H, Cox D, Pierce A, Grayson JW, Carroll WR (2020) Tracheotomy in the SARS-CoV-2 pandemic Head Neck 42:1392-1396

15 Damian B, Panayiotis K, Kevin S, Alistair S, Chetan K, Leandros V (2020) Surgical tracheostomies in Covid-19 patients: important considerations and the " 5 Ts" of safety Br J Oral Maxillofac Surg 58:585-589

16 Schultz P, Morvan JB, Fakhry N, Morinière S, Vergez S, Lacroix C, Bartier S, Barry B, Babin E, Couloigner V, Atallah I (2020) French consensus regarding precautions during tracheostomy and post-tracheostomy care in the context of COVID-19 pandemic Eur Ann Otorhinolaryngol Head Neck Dis 137(3):167-169

17 Foster P, Cheung T, Craft P, Baran K, Kryskow M, Knowles R, Toia A, Galvez C, Bowling A, DiSiena M (2020) Novel approach to reduce transmission of COVID-19 during tracheostomy J Am Coll Surg 230(6):1102-1104

18 Youn SH, Baek SY, Yoon J, Hong SS, Kim Y (2020) A case report of tracheostomy for a patient with COVID-19: how to minimize medical staff and patient risks J Kor Med Sci 35:28

Publisher's Note Springer Nature remains neutral with regard to jurisdictional claims in published maps and institutional affiliations 